\title{
Philipe Descola e a Virada Ontológica na Antropologia
}

\author{
Luiz César de Sá Júnior \\ Universidade Federal do Rio de Janeiro, RJ, Brasil \\ E-mail: luizdesajunior@gmail.com
}




\section{Resumo}

Este artigo pretende mostrar ao leitor um conjunto de teorias antropológicas, em vias de produção, que se inscreve num movimento filosófico geral chamado de "virada ontológica". Após realizar a síntese de alguns pressupostos fundamentais, será tratada a principal obra do antropólogo Philippe Descola, Par-delà nature et culture, na qual desponta uma elaboração teórica que concilia materiais históricos e etnográficos a teorias estruturalistas. Argumenta-se, por fim, que esse modelo pode ser proveitoso para as demais disciplinas do campo das humanidades.

Palavras-chave:Philipe Descola. Virada Ontológica. Antropologia Simétrica. Multinaturalismo.
Abstract

This article aims at introducing the reader to the ongoing set of anthropological theories that are part of a more general philosophical movement called "ontological turn". After performing the synthesis of some fundamental assumptions, it moves onto the main work of the French anthropologist Philippe Descola, Par-delà nature et culture, in which emerges a theoretical elaboration that combines historical and ethnographic materials with structuralist theories. In conclusion, it is argued that this model may be useful for other disciplines of the Humanities.

Keywords: Philippe Descola. Ontological Turn. Symmetric Anthropology. Multinaturalism. 


\section{Do Multiculturalismo ao Multinaturalismo}

expressão antropologia simétrica ${ }^{1}$, como todas as etiquetas acadê-
micas, porta um sentido que, do momento de sua confecção até agora, isto é, na passagem das últimas quatro décadas (Latour, 2007, p. 11), começa a exibir certo desbotamento ${ }^{2}$. Ainda assim, ela pode nos servir de ponto de partida para adentrar o universo da chamada "virada ontológica" na antropologia, de que Par-delà nature et culture, livro de Philippe Descola, é representante distinto, e ao qual me reportarei neste artigo.

O trabalho de romper com o dualismo que apartava as antropologias social e cultural, tradicionalmente à caça de "culturas", e as antropologias físicas e biológicas, interessadas pela "natureza", partiu da reconsideração desses conceitos por parte da antropologia simétrica. A multiplicidade de culturas que autorizava o exercício antropológico dependia, afinal, da estabilidade oferecida pelo conceito de natureza, homogêneo, frio e objetivo e, portanto, apto a exercer o papel de tercium comparationis. A natureza figurava também como meta a alcançar, algo que definiu o papel determinante da Ciência como instrumento medidor do progresso ocidental (para Bruno Latour, particularmente o europeu) e termômetro de práticas a ele desconhecidas. Se estaria diante de uma natureza geral, exterior ao homem, da qual não se sabe tudo, mas pode-se eventualmente saber, e o homem, em suas propriedades particulares, as quais, se bem que variadas e quase indecifráveis no espelho das múltiplas culturas, poderiam em, todo caso, recair em modelos essencialistas e determináveis. Latour oferece um exemplo claro quanto ao último aspecto: “[...] alguém pode registrar com muito mais facilidade as várias maneiras de compreender a concepção 
se souber que a fisiologia pode prover a única definição da maneira biológica de se ter filhos." ${ }^{3}$

Essa situação "clássica, ou melhor, moderna" (Latour, 2007, p. 13), culmina no estrangulamento da noção de multiculturalismo pela antropologia simétrica, pois ela não chegaria a qualquer ponto efetivamente profundo e não faria mais do que refratar apenas um "regime de discurso" ${ }^{4}$ ou, na formulação mais recente de Latour, um único "modo de existência"; a saber, o científico, embora este convoque para si o patrimônio inerente ao desvendamento de toda a realidade. No fundo, o multiculturalismo é entendido como eco regular e insípido da noção de natureza, esvaziada, ela mesma, de qualquer multiplicidade conceitual.

Indo além, seria legítimo argumentar que o impasse deriva de inconsistências de tipo ontológico. A antropologia tradicionalmente assumiu que cada cultura tinha vinculada a si a Natureza, explicada segundo "visões de mundo", que poderiam transformá-la em uma natureza particular. A questão se complica a partir da necessidade de que essa natureza fosse entabulada em um conceito de cultura que aglutinasse a perspectiva de natureza e de cultura que, unificadas, dariam o tom de uma sociedade. O sentido mais geral dessa sociedade, em seguida, só se veria explicado por uma concepção de natureza superior e estável, acima de todo o conjunto, e assim por diante, numa cadeia referencial potencialmente interminável. (Sztutman, 2009, p. 89)

O imbróglio acaba por desembocar na polêmica entre relativistas e universalistas. Eles optariam por compreender o conjunto de culturas humanas naquilo que lhes é próprio em conjunto, ou seja, sua Natureza comum. Já aqueles apostariam que cada cultura teria demarcada independência das demais, sendo incomparável às restantes devido a sua construção particular de natureza. No caso dos Modernos, teria prevalecido sua crença na própria modernidade (uma "modernidade em-si"), refletida por sua inclinação universalista, emaranhada do início ao fim à força absoluta da objetividade inerente à Ciência. Latour defende posição contrária, mas não relativista, no sentido espúrio que a crítica das humanidades lhe impingiu, à qual, revertida aos universalistas, render-lhes-ia o título de absolutistas, ${ }^{5}$ mas outra. Em vez 
de relativismo como impossibilidade imanente da busca do verdadeiro ou do real - melhor seria dizer, do único Verdadeiro e do único Real -, irrastreável no multiverso de naturezas e associações, organização relativista do pensamento, no sentido de traçar correspondências e associações num mundo ontologicamente plural (Latour, 2007, p. 16), o que não significaria, de modo algum, descartar as condições de verificabilidade de asserções científicas:

A tese essencial não seria tanto a de que há tantos mundos quanto pontos de vista, mas a de que esses mundos são reais, ou mais exatamente são a realidade, na falta desse mundo absoluto que só poderia ser captado desde um ponto de vista absoluto, o de Deus. Se tal opção filosófica pode ser pouco palatável para positivistas profissionais, não deveria ser difícil de assumir para os antropólogos e os humanistas em geral. O postulado, aparentemente extraordinário, de que cada ponto de vista define um mundo diferente se traduz na experiência singela de que cada sujeito age em função do que vê, e com isso realiza o que vê. O verdadeiramente extraordinário seria esperar que ele agisse de acordo com estruturas ou princípios gerais que não vê. E, no entanto, é isso que esperam outras epistemologias: que as ações obedeçam a regras gerais ou que, devidamente interpretadas, possam se fundir num horizonte comum. (Sáez, 2012, p. 15)

Crendo na solução relativista há pouco esboçada, há quem insista que toda a "querela" entre relativistas e universalistas faria pouco ou nenhum sentido, uma vez que, antes de tudo, suas definições de natureza e cultura difeririam, sendo mesmo impossível alcançar consenso. Uma solução para isso residiria no entendimento de daqueles para quem "[...] um verdadeiro relativismo - isto é, um perspectivismo -, nas palavras de Giles Deleuze, não afirma a 'relatividade do verdadeiro, mas a verdade do relativo'" (Sztutman, 2009, p. 91). Na mesma toada de Latour, acrescenta-se que o verdadeiro relativismo interessa-se pelo plano das relações, enquanto os "absolutistas" envolver-se-iam com a disputa pelo monopólio do Um, do "em-si". Eis a razão pela qual, exemplifica, Richard Dawkings e o papa se digladiam (inutilmente) apesar das evidentes disparidades ontológicas dos planos de sua enunciação. 
Eduardo Viveiros de Castro anteviu uma possibilidade de crítica a partir da falsa associação do multinaturalismo a um relativismo cultural $^{6}$, a qual poderia transformar a busca pela formulação de ontologias por um disfarce, como se este fosse apenas outro nome para cultura. No importante ensaio "Perspectivismo e multinaturalismo", ele teve a chance de sintetizar a posição ameríndia em termos que refutam essa leitura:

O perspectivismo não é um relativismo, mas um multinaturalismo. O relativismo cultural, um multiculturalismo, supõe uma diversidade de representações subjetivas e parciais, incidentes sobre uma natureza externa, una e total, indiferente à representação; os ameríndios propõem o oposto: uma unidade representativa ou fenomenológica puramente pronominal, aplicada indiferentemente sobre uma mesma diversidade real. Uma só "cultura", múltiplas "naturezas"; epistemologia constante, ontologia variável - o perspectivismo é um multinaturalismo, pois uma perspectiva não é uma representação. (Viveiros de Castro, 2011, p. 379) ${ }^{7}$

Philippe Descola acrescentou, anos depois, que as tratativas relativistas permitiriam, como quis Latour, reconciliar a investigação científica à pluralidade dos mundos e coletivos que compõem o planeta. Assim como nos depoimentos acima citados, Descola antevê uma solução que descarta o relativismo por seu congraçamento enquanto técnica relativista pronominal:

Eu a chamarei [a via de conciliação] sem dificuldades de universalismo relativo, não por provocação ou pendor por antifrases, mas tomando o epíteto "relativo" no sentido que ele tem em "pronome relativo", ou seja, aquilo que remete a uma relação. O universalismo relativo não parte da natureza e das culturas, das substâncias e dos espíritos, das discriminações entre qualidades primeiras e qualidades segundas, mas de relações de continuidade e de descontinuidade, de identidade e de diferença, de semelhança e dessemelhança que os humanos estabelecem por toda parte entre os existentes por meio das ferramentas herdadas de sua filogênese: um corpo, uma intencionalidade, uma atitude a perceber traços distintivos, a capacidade de manter com um 
outro qualquer relações de aliança ou de antagonismo, de dominação ou de dependência, de troca ou de apropriação, de subjetivação ou de objetificação. (Descola, 2005, p. 418-419) $)^{8}$

Caso se queira enxergar além da cortina de fumaça Moderna, tería-se que, segundo esses autores, investir na antropologia simétrica e na "virada ontológica" a ela vinculada. Esta aparece, assim, tanto como reabilitação da reflexão metafísica nas ciências sociais contemporaneamente quanto como dínamo da crítica, cada vez mais incisiva, ao paradigma nuclear dessas ciências, preservado desde sua geração, no século XVII: a referida oposição entre natureza e cultura (Viveiros de Castro, 2012, p. 152). Essa distinção, por sua vez, agrega diversas outras ("sujeito versus objeto", "discurso versus realidade", etc. ${ }^{9}$ ), estabelecendo o fio condutor do que se tem chamado de metafísica dos Modernos $^{10}$, sua mitologia particular, ou, para usar a logomarca de Bruno Latour, sua ontologia regional ${ }^{11}$. A natureza e a cultura que a definem, para retomar uma última vez a vulgata, à guisa de conclusão desta etapa, seriam os elos cosmológico e antropológico da existência, duas ordens estanques cujo entrelaçamento somente se daria com o esforço humano, sempre limitado, de perscrutar tudo aquilo que é não humano através das lentes da objetividade. A "virada ontológica", tendo nascido na filosofia epistemologicamente desconfortável com o correlacionismo antropocêntrico, instituiu-se no núcleo de trabalhos antropológicos que privilegiavam as metafísicas indígenas em tudo aquilo que elas poderiam nos ensinar (a nós, Modernos europeus e ocidentais), agora que foram alçadas à condição simétrica atinente à multiplicidade de naturezas possíveis (Viveiros de Castro, 2012, p. 167) e que se dispõem a propor um novo pacto para a auto-organização dos Modernos e para um tratamento mais dinâmico e simétrico com os demais coletivos.

Se o esforço de pluralismo ontológico ${ }^{12}$ irmana-se bem às metafísicas indígenas, faz sentido recorrer aos argumentos disponibilizados por um dos trabalhos que melhor e com mais potência perfilou as ambições ontológicas da antropologia simétrica e essas metafísicas, que frequentemente lhes servem de combustível: "Par-delà nature et 
culture", de Philippe Descola. Antes, esboça-se os caminhos trilhados por Descola até a escrita do livro, como seu prelúdio.

\section{Dilemas da Razão Prática: natureza e cultura entre os Achuar}

De acordo com a trama da própria reconstituição de sua carreira, Philippe Descola não se imaginava de maneira alguma na posição que viria a ocupar em 2005, com a publicação de "Par-delà nature et cultu$\mathrm{re}^{\prime \prime}$. O então jovem estudante, amálgama de iconoclasta da metafísica e filósofo medíocre ${ }^{13}$, que bateu à porta de Lévi-Strauss em busca de sua atenção e aconselhamento, queria mergulhar no empirismo mais profundo, o que o levou, como se sabe, à Amazônia e aos Achuar, onde passou alguns anos com sua companheira, Anne Christine ${ }^{14}$.

As peripécias desse estudante e seu relato delas dão o tom do percurso que o alçou à cátedra de "Antropologia da natureza" do Collège de France. A carreira de Descola percorreu um momento de grande rejeição à teoria, quando os interesses descritivos e a relutância em incorrer nas mal vistas macroanálises estruturalistas, acusadas de reducionismo, imperavam. Faz sentido, portanto, que sua obra tenha encontrado refúgio junto a Lévi-Strauss, uma vez que o estruturalismo podia prover-lhe a oportunidade concreta de construir uma etnografia adequada a seu rito de passagem no campo antropológico e vontade de empiria sem descurar da possibilidade de formulações de calibre teórico sobre o outro. Ou, como se vê, sem abandonar as proposições gerais como premissas mediadoras de voos mais altos, sempre ancorados, porém, em vertiginosa documentação e experiência etnográfica.

Eram já esses os pressupostos do primeiro livro do autor, de 1986. Tese de doutorado orientada por Lévi-Strauss, "La nature domestique" propunha um mapeamento das circunstâncias técnicas e simbólicas das relações dos Achuar com seu ambiente natural a partir de um conjunto de proposições marcantes. Oscilando entre os espíritos de "geometria" e "finesse", constitutivos do exercício antropológico, mas usualmente separados pela navalha do pragmatismo imposto, de resto, a cada pesquisa e a cada pesquisador submetidos à angústia do produtivismo, Descola oferecia uma análise que se destinava a recobrir 
tanto o território especulativo de uma “[...] intuição demonstrável pela coerência dos encadeamentos lógicos que ela autoriza [...]" quanto os aspectos contingenciais de pesquisas de "[...] séries recorrente empiricamente verificáveis pelo trabalho estatístico". (Descola, 1986, p. 2$)^{15}$.

Este casamento difícil entre "quantificação e hermenêutica", radicado numa separação de bens epistemológicos situados nas esferas objetivistas da "natureza" e da "cultura", parece rumar ao fracasso por, segundo Descola, se ater a domínios que foram criados por causa da economia da exposição de um texto como se eles fossem instâncias específicas, e não formas distintas de aproximação a dado objeto. É adequado lembrar que Descola falava de um lugar em que essa distinção era extrema, a saber, a encruzilhada entre o apreço filosófico por Althusser e a aura de "dogmatismo letárgico" que o cercava e a experiência de "humildade" que apenas uma etnologia de "estranhas instituições exóticas" poderia oferecer (Descola, 1986, p. 3). Instituições que seriam iluminadas pela exegese do cotidiano e pelas exíguas coordenadas de Lévi-Strauss e Godelier que conseguira apreender, cujas obras conhecia o necessário para "preparar uma aula brilhante sobre a noção de estrutura, isto é, muito poucas coisas"16 (Descola, 1986, p. 3)

Foi armado com elas que procedeu à tarefa de socialização da natureza, bastante ingrata se considerar, com Descola, que, de Oviedo a Buffon, o território amazônico foi dominado por um naturalismo que o classificava como uma "[...] espécie de conservatório botânico e zoológico, muito acessoriamente habitado por homens" ${ }^{17}$ (Descola, 1986, p. 10). De fato, a inexistência, entre os Achuar, de uma narrativa coerente e sistemática de interpretação do mundo dava falsa pertinência ao utilitarismo que nos levaria a pensar que aquela era uma sociedade sem cultura. Desconfiado desse paradigma, Descola investiu numa tentativa de bricolagem que se orientava a partir do conteúdo simbólico das práticas, sem estabelecer hierarquias imanentes entre mental e real. Assim, viabilizava o percurso de uma praxis organicista, que fundia ambos os aspectos (usos do meio ambiente e suas representações) para forjar o complexo objeto intitulado por ele de "estrutura das práticas" (Descola, 1986, p. 12), cujo centro é, no caso dos Achuar, o âmbito doméstico ${ }^{18}$. 
Em resenha publicada no Anuário Antropológico, em 1988, Mauro W. B. de Almeida lança luz sobre as propostas de Descola e o debate em torno do qual a tese fora preparada. Sintomático da escaramuça intelectual em curso é o próprio percurso da resenha, que escolheu partir da versão amazônica do "jogo de soma zero" entre estruturalistas e materialistas para só então tratar de "La nature domestique". O fator de desequilíbrio introduzido por Descola nesse jogo era precisamente o fazia de seu livro um empreendimento "excitante". (Almeida, 1988, p. 213)

De maneira bastante incisiva, Almeida apontava para aquilo que Lakatos chamou de "degeneração de um programa de pesquisa" nesses embates amazônicos. Na maior parte dos casos, os aspectos materiais vinham ao centro das investigações; se explicados a partir de circunstâncias culturais, ou se estas fossem explicadas sem recorrer àqueles, ocorria uma vitória estruturalista, enquanto a resolução do "enigma da cultura" por meio do "desafio materialista" resultava em derrota (Almeida, 1988, p. 214-215). O livro de Descola seria um representante do "paradigma inclusivo", no qual ecologia e economia empreendiam potente simbiose, passível de descrição por meio de dispositivos presentes em ambas as teorias ${ }^{19}$ (Almeida, 1988, p. 218). O meio doméstico seria uma unidade técnica propícia a esse encontro, na qual não valeria o imperativo material produtivista (termo ademais estranho àquele coletivo); "ao contrário", sintetiza Almeida, “[...] a sugestão é de que a forma exacerbadamente 'doméstica' de sociabilidade Achuar é guiada, além das exigências materiais imediatas, pela ideia de autonomia embutida na cosmologia Achuar". (Almeida, 1988, p. 219)

Das várias colocações críticas de Almeida, uma resulta particularmente importante, pois retornará à pauta daqueles que se indispuseram com conclusões que Descola viria a desenvolver em "Par-delà nature et culture". Uma vez que Descola decidiu isolar o núcleo doméstico como referência possível para organizar sua análise dos Achuar, isso implica assumir que eles “[...] compartilham um mesmo conjunto virtual de técnicas e representações e que estas são parte da competência de todos". O corolário dessa sugestão é óbvio: a hipótese de Descola "postula justamente aquilo que o livro deveria provar", isto é, 
a unificação das ordens simbólica e material (Almeida, 1988, p. 220). Ao fim e ao cabo, Descola acabaria enredado nas teias de um conflito teórico europeu, cuja resposta, seja como hipótese, seja como ponto a provar, acabaria incidindo decisivamente sobre a leitura dos Achuar. Ser obrigado a retomar a consideração evidente de que a reconstituição daquela cosmogonia passava por filtros naturalistas poderia soar a muitos como pedágio necessário a pagar no curso de qualquer investida antropológica; mas, pensada no interior do mais amplo debate sobre os conceitos de natureza e cultura, cujo curso viria a imiscuir-se em seu projeto intelectual, provar-se-ia insidiosa.

\section{A Antropologia da Natureza e as Quatro Ontologias}

O resultado alcançado pela tese não delimitou o fim da pesquisa de Descola em torno dessas questões. O passar dos anos permitiu-lhe reunir elaboração metafísica e empiria para além das expectativas geradas pelo trabalho inaugural, e essa estratégia fez com que a combinação de teoria e "grand récit" encampada por "Par-delà nature et culture" ecooasse veementemente no cenário intelectual francês (Bloch, 2007, p. 181). Far-se-á o mapeamento de sua proposta geral e de críticas e possíveis respostas frente a seus argumentos capitais.

O propósito declarado de "Par-delà nature et culture" é, como indica o título, desautorizar a ideia de que "natureza" e "cultura" devem ser duas categorias universalmente apartadas, consideração que só faria sentido aos Modernos e, mesmo entre eles, apenas a partir da metade do século XVII. Para além das evidentes implicações no estudo de outras sociedades, essa hipótese, caso confirmada, permitiria repensar as metodologias e objetivos da própria antropologia (Descola, 2005, p. 13), cujas bases estariam, nesse sentido, viciadas.

Sua proposta de reordenamento do campo passa, precisamente, por uma crítica ao empirismo isolado, isto é, que ignore fatores estruturais. Em suas próprias palavras, queria afastar-se do "historicismo, e de sua fé ingênua na explicação por meio de causas antecedentes", sendo necessário ter em vista "vigorosamente que somente o conhecimento da estrutura de um fenômeno permite se interrogar de modo pertinente sobre suas origens ${ }^{20 \prime \prime}$. Fiel a sua formação, Descola reconhece de 
partida, porém, que esse conhecimento estrutural só foi formulado na sequência de uma "experiência etnográfica muito particularizada ${ }^{21 "}$.

No convívio com os Achuar, Descola começou a amadurecer a alternativa ao binômio em questão partindo do princípio de que a natureza não gozava, entre os índios, de estatuto singularizado, nem tampouco remetia-se à tipologia de objeto "utilizado" ou "utilizável", mas era, antes, tida por sujeito participante das relações sociais. A categoria de "sujeito" é relevante, pois orienta o entendimento de que aquela cosmologia qualificava espíritos, plantas e animais como entes dotados de alma, não havendo, portanto, pesada discriminação ontológica entre humanos e não-humanos, ou seja, os coletivos ${ }^{22}$, senão do ponto de vista da hierarquia que separava uns de outros (Descola, 2005, p. 23$)^{23}$. Para mais, sobressaía a congruência de sua interioridade. (Descola, 2005, p. 176)

Exibindo uma das principais qualidades do livro, a saber, sua capacidade de antever potenciais armadilhas e dar respostas a possíveis críticas e indagações no interior do próprio projeto, Descola imediatamente se pergunta quanto à possibilidade de que os Achuar constituíssem exemplo tão isolado que dificilmente poderia explicar mesmo o panorama mais vasto das populações indígenas da América do Sul. Eis o instante em que, exercitando bem o dispositivo discursivo que une autocrítica e captatio benevolentiae ${ }^{24}$, aliás, reciclado de sua experiência com a escrita de "La nature domestique", Descola amplia o escopo de grupos cuja perspectiva não era dualista, passando aos Makuna da Colômbia oriental e, um tanto rapidamente, para a conclusão de que cosmologias semelhantes figuram em diversos territórios. O que vai se constituindo como um modelo acaba por fazer frente à prova de fogo da distância, pois Descola constata a persistência de cosmologias aparentadas àquelas dos povos amazônicos em localidades milhares de quilômetros ao norte, como entre os índios da região subártica do Canadá $^{25}$. Antes que se lhe possa indagar, recusa, por fim, a possibilidade de que as coincidências sejam meramente sintonia de uma linguagem metafórica comum (Descola, 2005, p. 35), e isso graças à concordância estrutural de suas práticas e esquemas interpretativos ${ }^{26}$.

Está armada a fundação que sustentará a pergunta central de Descola. Se as experiências recolhidas e sistematizadas após o convívio 
com os Achuar podem de fato superar vínculos superficialmente metafóricos ou relações ideológicas além de tudo entravadas por distâncias geograficamente significativas, pode-se concluir pela existência de traços estruturais que deem conta da proximidade de suas visões de mundo, ou melhor, de seus próprios modos de viver. E se é verdade que uma estrutura como essa - que se chame de ontológica - pode ser verificada entre os índios, provavelmente valeria ir além e organizar dispositivos inerentes a outros grupos, cartografando, mas não somente, os próprios ocidentais. (Descola, 2005, p. 52-56)

A morfologia empregada por Descola para reportar as ontologias que constituiu parte de um princípio lógico-analítico bastante sólido. Trata-se do que ele chama de "[...] duas modalidades fundamentais de estruturação da experiência individual e coletiva [...]" (Descola, 2005, p. 163), nomeadas por ele "identificação" e "relação" ${ }^{27}$. A identificação traduz-se como o esquema primitivo de mediação entre o ente e os demais existentes, entre o "soi" e o "non-soi", forma elementar, assim, de registro de continuidades e descontinuidades; a relação, como mecanismo de correspondência entre os entes ${ }^{28}$. Ambos, em seguida, se desdobram em outro par, tomado da filosofia de Husserl, qual seja, "fisicalidade" e "interioridade", completando o dispositivo. As relações de semelhança e dessemelhança entre as fisicalidades e as interioridades geram quatro ontologias: animismo (semelhança de interioridades, diferença de fisicalidades), totemismo (semelhança de interioridades, semelhança de fisicalidades), naturalismo (diferença de interioridades, semelhança de fisicalidades) e analogismo (diferença de interioridades, diferença de fisicalidades) (Descola, 2005, p. 176). Observa-se, de modo esquemático, quais são suas características principais, seguindo de perto considerações recentes de Descola.

A ontologia animista está presente em regiões da América do Sul e do Norte, e também na Sibéria e em partes da Ásia. Sua característica principal é a imputação de subjetividade a plantas, animais e outros elementos do ambiente físico de modo a estabelecer relações pessoais com eles. Sua participação naquilo que se chama de vida social é concebível graças à continuidade de interioridades pressuposta; ela é expressa, na maior parte dos locais onde prevalece o animismo, pela ideia de que a humanidade é uma condição universal. As diferenças 
entre os seres ficam evidentes pela descontinuidade de seus corpos. Muitos coletivos animistas investem nessa diferença ao designar a possibilidade de que os corpos sejam descartados, o que garantiria a portabilidade da interioridade. Isso, contudo, não impede que os corpos sejam valorizados, já que eles são mais do que meros signos da "alma", apresentando-se como equipamentos biológicos que identificam espaços apropriados para as espécies, seu Umwelt. (Descola, 2014, p. 275)

A ontologia totemista é bem menos recorrente que as demais, sendo melhor exemplificada pelos aborígenes da Austrália. Os seres dessa ontologia compartilham atributos organizados por um totem. O totem, geralmente um animal ou planta batizado com o nome de uma propriedade abstrata (e não um nome atrelado à espécie, por exemplo), congrega um grupo de humanos, que compartilham, por meio dele, disposições físicas e comportamentais. O nome do totem designa as propriedades da espécie, de modo que o que liga humanos e não humanos não é o aporte "natural" ou zoológico, mas a cadeia de analogias que agrega as descontinuidades evidentes entre eles. (Descola, 2014, p. 275-276)

A ontologia analogista reúne uma dupla série de diferenças, partindo do pressuposto de que as entidades do mundo correspondem a uma multiplicidade de formas e essências separadas por pequenos intervalos, sendo frequentemente organizada segundo uma cadeia que organiza e vincula atributos presentes no mundo (Descola, 2014, p. 276). É possível detectá-las nas técnicas divinatórias chinesas; nos coletivos africanos que creem haver reciprocidade entre desordens sociais e catástrofes naturais; e na medicina europeia dos séculos XV -XVII, na qual prevalecia a busca de analogias entre sintomas, objetos e partes dos corpos humanos (Descola, 2005, p. 280-281). A analogia transformou-se, nas muitas variações da ontologia analogista, em recorrência cotidiana para explicação do mundo, às vezes tornando-se "maníaca" na medida em que o anseio pela completude hermenêutica revela-se crucial. A única forma de ordenar um regime de diferenças de interioridade e de fisicalidade é empregar a semelhança. Ela aparecia como a designação de trajetórias que podiam se repetir em seus termos (metáfora) ou em suas relações (metonímia). No caso dos 
primeiros, trata-se de uma relação avizinhada, visível, enquanto nos segundos valia a "simpatia", uma afinidade à distância. Em todos os casos existem signos a identificar (Descola, 2005, p. 285-287). Tendo sido predominante também entre as populações do México no século XVI, é possível argumentar, via analogismo, que os astecas pareciam bem menos misteriosos aos europeus do que as expressões modernas deste encontro permitem enxergar. (Descola, 2005, p. 289)

A ontologia naturalista seria aquela em que se vive. Ele designa o pressuposto, surgido convencionalmente em meados do século XVII europeu, de que há um domínio ontológico determinista chamado "natureza", em que leis gerais poderiam explicar eventos e onde nada aconteceria sem uma causa. Ao mesmo tempo, a ontologia naturalista privilegia a qualidade do artifício humano, sua livre invenção, cuja complexidade teria sido domesticada no curso do aparecimento de ciências voltadas a ela ao longo do século XIX. Os alvos dessa domesticação seriam denominados "culturas". O naturalismo parte de premissa oposta à do animismo, pois a continuidade é material, própria dos elementos da "natureza", onde nada nem ninguém existe singularmente, enquanto a descontinuidade é interior, expressada pela mente e pela alma e seus corolários - língua, moral. Essa classificação muitas vezes agrega os humanos, em fusão que gera uma nova marca de descontinuidade interior; é por isso que prevaleceu por muito tempo a ideia de designar um povo por meio de seu "espírito", volksgeist, génie du peuple. (Descola, 2014, p. 277)

Duas tentativas de críticas poderiam se impor a esses dispositivos. A primeira salta logo aos olhos quando somos tentados a associar a posição dualista de Descola à dinâmica entre corpo e alma, comum aos ocidentais. Fosse válida essa leitura, não custaria atacá-lo sob o argumento de que as quatro ontologias acabam por se estruturar mediante os critérios da ontologia regional de que faz parte. Recordemos, ademais, que já em "La nature domestique" aparecia essa dificuldade de dicção, que enxergava um continuum entre natureza e cultura que no entanto acabava algo enredado em manifestações descritivistas propriamente naturalistas. Mas Descola inteirou-se dessa ameaça, e é no próprio livro que a refuta, sustentando que, antes de tudo, a distinção entre corpo e alma extrapola em muito os esquemas ocidentais 
- e, se haveria algum dualismo mais restrito a ele, seria sem dúvida o que opõe natureza e cultura (Descola, 2005, p. 175). Mas poder-se-ia ir mais longe, diz, acrescentando que as chances de que haja contaminação da ontologia particular na descrição das demais é algo com que se pode contar. Bastaria enfatizar que o pensamento naturalista tem predileção por classificações muito parecidas com aquela há pouco esboçada. Nada a temer se admitir que, de fato, o empreendimento de Descola não recusa sua origem (Descola, 2005, p. 337); muito pelo contrário, procura inscrever-se nela.

A segunda crítica marcaria a frágil armadura heurística em que o livro parece se amparar frente à descomunal tarefa de descrever ontologias em escala planetária. Nesse caso, Descola teve a oportunidade de se esclarecer quando respondeu ao conjunto de observações de Jean-Pierre Digard logo na sequência da divulgação do livro. Na ocasião, lembrou que seus instrumentos não se prestam a esclarecer as particularidades dos grupos, algo que só poderia se descortinar com uma combinação de trabalho etnográfico e histórico "delirante". Seria preciso encará-los como ferramentas heurísticas, cujo design permitiria estabelecer analogias de nível estrutural, explicando a persistência de certos comportamentos, mitos, etc. ${ }^{29}$. Nos termos do próprio Descola, mesmo os objetos estudados a partir dessas ontologias não são sínteses ad hoc de representações e práticas totalizadas, mas conjuntos de características “[...] abstraídas de descrições da vida social de modo a salientar algumas de suas propriedades. ${ }^{30 "}$ (Descola, 2014, p. 274)

O próprio livro também se defrontou com esse aspecto. Quando conclui sua elaboração das quatro ontologias, Descola passa a discorrer contra a objeção - que todavia considera racional - em torno de sistemas tão elementares.

Poder-se-ia objetar com razão que o mundo e seus usos são complexos demais para serem reduzidos a esse gênero de combinação elementar. Lembremos então que os modos de identificação não são modelos culturais ou habitus localmente dominantes, mas esquemas de integração da experiência que permitem estruturar de modo seletivo o fluxo da perceção e a relação com o outro por meio do estabelecimento das semelhanças e das diferentes entre as coisas a partir dos recursos idênticos que cada um 
carrega consigo: um corpo e uma intencionalidade. Os princípios que regem esses esquemas, sendo universais por hipótese, não poderiam excluir uns aos outros, e podese supor que eles coexistem em potencial em todos os humanos. Um ou outro dos modos de identificação tornase, é certo, dominante em tal ou qual situação histórica, e encontra-se assim mobilizado prioritariamente na atividade prática e nos julgamentos classificatórios, sem que seja por isso aniquilada a capacidade que têm os três outros de se infiltrar ocasionalmente na formação de uma representação, na organização de uma ação ou mesmo na definição de um campo de hábitos. (Descola, 2005, p. 322$)^{31}$

A capacidade de encontrar diversos aspectos das ontologias em tempos e lugares cruzados é fundamental, e talvez seja a situação mais comum a verificar nas sociedades ou coletivos estudados, pois as oscilações de dominação ontológica não podem ser medidas senão em larga duração temporal. As combinações resultantes seriam altamente complexas, mas, mesmo assim, evidenciariam regularidades próprias das estruturas organizadas pelos modos de identificação e de relação. (Descola, 2014, p. 277)

Essa arquitetura aponta para um fator adicional a ser considerado, que é de suma importância. Pode-se captá-lo por meio de entrevista recente do autor, publicada pela Topoi, revista de História. Quando perguntado sobre os passos que o levaram a este curioso oxímoro que é "antropologia da natureza", engrenagem principal do livro de 2005, Descola argumenta:

Então, ao longo do tempo, fabriquei este modelo em etapas sucessivas, acrescentando-lhe peças e corretivos, de tal modo que, na sua forma se não definitiva, em todo caso a mais acabada (a que forneci em Par-delà nature et culture), tem-se a impressão de que se trata de um dispositivo hipotético dedutivo oriundo de uma operação antropológica clássica e não de uma generalização etnográfica por indução. Mas, na verdade, sem entrar no detalhe das etapas sucessivas que resultaram nesse modelo, é evidente que ele tem uma aparência um tanto artificial de completude que não revela nada sobre os arcabouços progressivos que a etnografia, a etnologia e a 
discussão com os colegas etnólogos permitiram construir. Devo dizer, mais uma vez, que tenho uma formação filosófica, e uma das características da filosofia ocidental é a obsessão pelos fundamentos, de que é muito difícil se desvencilhar. (Descola, 2013, p. 496)

[...] Mas eles me pareceram necessários para poder construir com mais segurança a minha análise a partir de um dispositivo simples. Por que um dispositivo simples? Porque há muito tempo sou partidário da navalha de Occam: as soluções filosóficas, lógicas ou matemáticas mais simples e elegantes são frequentemente as mais eficazes e produtivas. Daí o modelo que desenvolvi de um sujeito transcendental - mais uma vez, é uma ficção totalmente eurocêntrica, mas pouco importa - que vai detectar ou não continuidades ou descontinuidades entre si, como sujeito dotado de um aparelho de detecção, cognitivo, simples, e o que ele observa à sua volta. E isso ele pode fazer graças a duas ferramentas principais que denominei "interioridade" e "fisicalidade". (Descola, 2013, p. 497)

As etapas de uma elaboração significativamente filosófico-antropológica impeliram Descola a uma espécie de modelo móvel ("um pouco como uma máquina experimental"), cujas articulações podem alterar-se ou mesmo desaparecer conforme o progresso da pesquisa. Estas convivem, por outro lado, com dados prévios pretensamente universais, a saber, os dispositivos de identificação e relação, sem os quais não seria possível propor o restante da démarche. Observa-se mais de perto os esquemas cognitivos que presidem à formação desses dispositivos.

\section{Estruturas e Esquemas da Prática}

A mecanicidade das estruturas ${ }^{32}$ tem sido o principal alvo de seu descrédito enquanto dispositivo analítico no âmbito das ciências sociais, razão pela qual Descola precisou remover certas dúvidas do caminho antes de passar à descrição tanto de seu conceito de estrutura quanto daquele de "esquema".

É assim que, na seção "Les schèmes de la pratique", Descola vê-se na necessidade de evocar um princípio estabelecido por Kant 
para justificar o alinhamento entre uma "fisiologia das interações", própria do território da experiência, e uma "morfologia das práticas", decompostas em suas unidades mínimas para facilitar o processo de extrapolação explorado por "Par-delà nature et culture". Esse esforço origina-se, portanto, da percepção kantiana de que estruturas sem conteúdo são tão vazias quanto experiências não dotadas de forma ${ }^{33}$.

Pensar em práticas orientadas por formas nada tem a ver com um frio automatismo conduzido por estruturas desmembradas dos agentes. Para Descola, é preciso desembaraçar a confusão entre as categorias, abrindo espaço para um conceito de estrutura afinado àquele de habitus. Seguindo os passos de Bourdieu, seria necessário assumir que as estruturas formam-se dentro de sistemas de valores calcados pela contingência das experiências históricas acumuladas pela interiorização imitativa e pelos circuitos da prática. Mas é além dos estratagemas de Bourdieu, mesmo admitindo sua eficácia ${ }^{34}$, que se encontra as soluções para as dificuldades com as quais este estruturalismo tem de se haver.

Descola propõe-se a aceitar a lógica do habitus, procurando estruturas que, todavia, o precedem. Tratar-se-ia de uma matriz originária ("matrice originelle"), ontologicamente definida como "um pequeno número de esquemas práticos interiorizados", por oposição a esquemas mentais imanentes. Em clara dívida para com "Estruturas elementares do parentesco" de Lévi-Strauss, Descola firma compromisso tanto com estruturas concebidas a partir do contato com o mundo quanto com mecanismos inconscientes elementares capazes de mediar as interações entre o inteligível e o empírico (Descola, 2005, p. 139-144). Os esquemas cognitivos de mediação conquistaram muita atenção entre teóricos da Gestalt e mesmo no meio dos pesquisadores da neurociência. Servindo-se deles e das reflexões de Roy D'Andrade em "The development of cognitive anthropolgy", Descola chega a

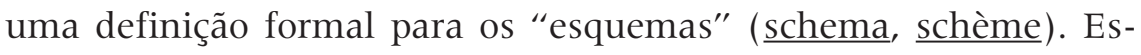
quemas seriam estruturas interpretativas específicas (teoricamente quantificáveis) atividades por imputs mínimos que desenvolvem o reconhecimento (Descola, 2005, p. 563). Os esquemas seriam móveis e flexíveis, "fragmentos de um saber tácito", e de maneira alguma 
requereriam o conjunto completo de atributos para determinada atribuição de sentido. Os traços esquemáticos de uma casa, por exemplo, poderiam estar apenas parcialmente presentes ou em diversos segmentos de configuração e ainda assim seriam reconhecidos - afinal, uma casa em ruínas continua uma casa, e um iglu pode ser definido como casa apesar da distância formal que se nos apresenta ao observá-lo (Descola, 2005, p. 144-145). Precisamente por sua compleição genérica e adaptável, os esquemas podem ter ativado comportamentos humanos e não humanos semelhantes em situações contingenciais absolutamente distintas, que passam a ser comparáveis num plano histórico-antropológico. (Descola, 2005, p.154-156)

\section{A "Virada Ontológica" e a Renovação Teórica das Ciências Humanas}

A proposta de Descola, muito embora rigidamente confinada em suas quatro ontologias e esquemas elementares, parece mais sólida que a de modelos alternativos, como o recentemente lançado por Bruno Latour. Sem propor qualquer comparação densa entre os livros, notese que, em Latour, com a admissão de inúmeras outras ontologias, chamadas por ele de "modos de existência" - inicialmente quinze em "Enquête sur les modes d'existence", potencialmente muitas mais - ocorre a possibilidade subjacente (eis a chave do problema e a diferença que se quer apontar) de que a ontologia regional dos Modernos fique dotada de uma variedade de modos de existência indisponíveis nas ontologias indígenas (basta pensar que o empreendimento, se bem-sucedido, ocasionará inúmeras pesquisas adicionais em torno da "antropologia dos Modernos", "descobrindo" novos modos de existir), discrepância suficiente para intuir a permanência de sua supremacia frente a outras formas de organização, algo que nem de longe consta do projeto intelectual e ideológico de Latour.

Por outro lado, uma característica a unir os dois trabalhos adviria dos dispositivos de organização da experiência, que, combinando a empiria do observador às estruturas teóricas numa espécie de fita de mobius, irmanam-se, finalmente, aos próprios relatos dos indivíduos que vivem no interior das ontologias, cujas percepções, se bem que, 
muitas vezes contraditórias ao que efetivamente se verifica em suas práticas (sobretudo entre os Modernos), são fundamentais para que não se ignore o que os atores têm a dizer de si mesmos. Esse predicado, colhido nas experiências antropológicas com as metafísicas indígenas, confere sentido especial à antropologia simétrica em sua "virada ontológica". E ajuda-nos, finalmente, a escapar do encarceramento que a Objetividade inerente à Ciência Moderna relega a outras formas de existências não validadas por Si. Não se está aqui, é óbvio, diante de uma negação da análise científica, jamais reduzida (nem em Descola, nem em Latour) à qualidade de mito entre outros ${ }^{35}$. Trata-se, na verdade, da substituição da Ciência pelas ciências $^{36}$. Essa forma de relativismo, alimentada por certa crença no poder explicativo do universalismo, dá tons muito maduros à discussão referida no início deste comentário. Trata-se, em suma, de defender que os muitos mundos e seres do planeta podem e são compostos de maneiras distintas, sendo necessário acessá-los para além dos critérios exclusivos de nossa ontologia. (Descola, 2014, p. 279)

Se Latour e Descola reagem a seus respectivos trabalhos de forma complementar e por vezes polêmica, o mesmo deve ser dito a respeito de outro par, aquele formado por Descola e Viveiros de Castro.

Bruno Latour recapitulou com grande vivacidade um encontro ocorrido entre eles em Paris no ano de 2009 texto de título sugestivo: "Perspectivismo: 'tipo' ou 'bomba'?" Ali, Latour relata que a amizade de vinte e cinco anos entre Viveiros e Latour não impediu a realização de uma discussão intensa, em que a admissão da importância dos trabalhos de um e de outro somou-se a críticas insinuadas desde há muito em conferências e publicações. (Latour, 2011, p. 173)

Da parte de Descola, referiu-se ao trabalho do colega como fundamental na constituição do ataque ao binômio "natureza-cultura", uma vez que seu conceito de anismismo tinha muito a ver com as pesquisas de Viveiros de Castro em torno do perspectivismo. Graças a esses esforços, teria sido possível postular um mundo, comemora Latour, "livre da unificação espúria de um modo naturalista de pensar" (Latour, 2011, p. 175). Este não impediria o universalismo tão caro aos naturalistas, mas o redefiniria em termos distintos e mais sofisticados, a saber, as quatro ontologias em suas dinâmicas estruturais. 
Viveiros de Castro expressou seu desconforto com a interpretação de Descola por meio de uma série de sugestões, mas poder-se-ia escolher uma delas como entrada à discussão: o conceito de perspectivismo seria, na visão do antropólogo francês, uma forma regional do animismo, e que teria sido explorada a fundo por Viveiros, produzindo o tipo de discrepância entre modelo e tipo que uma leitura tão abrangente quanto a de "Par-delà nature et culture" não poderia alcançar. Viveiros de Castro discorda completamente dessa posição, na medida em que sua definição de universalismo é "ainda mais radical" (Latour, 2011, p. 175). Reconhecendo a crítica à permanência do naturalismo como chave de leitura de Descola, Viveiros de Castro esclarece que o perspectivismo, antes de ser tipo, é bomba: não quer compactuar com a confraria dos "antropólogos republicanos" que insistem em impor categorias catequéticas - nalguns casos, de todo caquéticas - ao pensamento amazônico. O problema não está, portanto, no estruturalismo, mas no determinismo político que acompanha o debate natureza versus cultura.

Ciente de que a Ciência não é entidade pertinente para se contrapor às muitas políticas do exercício intelectual, Viveiros de Castro não recusa a patente ideológica de sua reflexão. Descola, com a melhor das intenções, teria construído, bem ponderadas as coisas, mais um cômodo no amplo Wunderkammer ocidental, negando, assim, a luta ameríndia por reconhecimento ontológico e pela descolonização do pensamento (Latour, 2011, p. 176). Viveiros de Castro pondera que Descola não é apenas um naturalista, mas também um analogista, na medida em que é "[...] possuído pelo cuidadoso e quase obsessivo acúmulo e classificação de pequenas diferenças a fim de preservar um senso de ordem cósmica ante a constante invasão de diferenças ameaçadoras". (Latour, 2011, p. 176)

Sem essa última volta do parafuso, o padrão-ouro kantiano permaneceria no controle, e o pensamento ocidental em nada ganharia com o ameríndio. A bomba fica, assim, desarmada, e o que significaria uma descrição engajada - ainda que racionalista, academicista e, em suma, naturalista - das muitas formas indígenas de agir, de sua cosmopraxis, viria a se tornar, no fundo, mais um episódio da luta teórica 
europeia. Não se engajar, nesse sentido, equivaleria a escrever mais um capítulo da longa trajetória de Paris no Pará. Latour encerra seu resumo referindo-se a isso: “A essa crítica Descola respondeu que ele não estava interessado no pensamento ocidental, mas no pensamento de outros; Viveiros de Castro replicou que a sua maneira de estar 'interessado' é que era o problema". (Latour, 2011, p. 177)

Apesar das claras divergências, é possível estabelecer, ao menos no que diz respeito ao debate mais abrangente do universalismo, pontos em comum ${ }^{37}$. Afinal, uma das grandes conquistas de "Pardelà nature et culture" é nos convencer firmemente da impossibilidade - e inutilidade - da oposição entre relativismo e universalismo. Aquele seria muito melhor aproveitado se ambicionado em termos de correspondências entre as diversas ontologias do mundo em seus modos específicos de relação e identificação. Este, admitindo que a condição estável da natureza humana (sem obliterar espaços para as contingências de suas práticas), hipotética e convencionalmente invariável, não funciona como vetor de explicações automatizadas, mas como circuito e esquema intermediário que reúne potencialidades biológicas a comportamentos da ordem da prática numa metateoria (Descola, 2006, p. 434). E, numa teoria que pretende explicar todas as teorias, quaisquer caminhadas à beira do abismo valem o risco, já que, findo o caminho, poder-se-ia divisar o aperfeiçoamento das humanidades como um todo, para não falar de ganhos políticos que, mesmo não estando no horizonte imediato de Descola, que fez da nostalgia combustível de seu minucioso exame, possivelmente contam com sua simpatia. Razões pelas quais "Par-delà nature et culture" não é apenas um sucesso antropológico, mas marco notável no campo das ciências humanas.

\section{Agradecimentos}

Este texto foi elaborado a partir de seminários de pós-graduação coordenados por Andrea Daher e Eduardo Viveiros de Castro, a quem gostaria de agradecer. Endereço, ainda, meus agradecimentos ao parecerista anônimo, que me ofereceu indicações preciosas. Os eventuais equívocos são de minha total responsabilidade. 


\section{Notas}

1 A expressão designa, grosso modo, o esforço de direcionar a antropologia para a indagação dos próprios modernos naquilo que eles têm de central. Destina-se especificamente a abandonar os locais comuns de investida no Ocidente civilizado, como periferias, cultos religiosos minoritários, etc., permitindo uma investigação da Ciência, do Direito e outras instituições, com o propósito de transpor seus praticantes à condição de "nativos" do ponto de vista da disciplina. Um exemplo inaugural desse esforço encontra-se em Latour e Woolgar (1996). Adicionalmente, a antropologia simétrica pretende conferir aos nativos tradicionalmente assim designados, notadamente os indígenas americanos, a capacidade de elaborar teorias acerca de suas próprias sociedades e as de seus visitantes. "Nativos e antropólogos", em suma, "[...] ressurgem como posições precárias, reversíveis e intercambiáveis, assim como o são humanos e não-humanos para o perspectivismo ameríndio". (Sztutman, 2009, p. 15)

2 A noção de "antropologia simétrica" surgiu do trabalho de Bruno Latour, e sempre esteve muito próxima de sua teoria do ator-rede (ANT), vulgarizada com Latour (2005). Contudo, a relevância da ideia de rede, tal como tomada pela ANT, começou a cair por terra com a obra mais recente do próprio Latour (2012), cujos desdobramentos poderão incidir diretamente, por conseguinte, no próprio conceito por ele arquitetado.

3 "For example, one can register so much more easily the various ways of understanding conception if one knows that physiology provides the one and only definition of the biological ways of having childen". (Latour, 2007, p. 13)

4 "Regimes of speech" era a formulação apresentada por Latour em seminário conduzido por Philippe Descola no Collège de France em 2003, quando as pesquisas que culminariam em EME estavam longe de terminar. Ela basicamente procurava destronar a ideia de uma "Ciência" em nome de "ciências", cujas naturezas específicas incidiriam em seus regimes internos de verdade. É essa a tese muito desenvolvida por $E M E$, e que resultou na fundação do conceito de "modos de existência". (Latour, 2007, p. 29)

5 A ideia retornará em EME, quando Latour identificará a propensão a empregar o termo "relativista" de maneira pejorativa, o que poderia ameaçar seu argumento antes que ele pudesse ser lido. "Bien plus, par une perversité dont il faudra comprendre plus tard les origines, ce diable (car c'est vraiment un diable!) s'est mis à stigmatiser, sous l'expression de 'relativistes', ceux qui veulent que la raison paye en réseaux les moyens de son extension. Sans voir que la position inverse, celle qui prétend qu'il existe des déplacements sans transformation, ne mériterait pas d'autre étiquette que celle 'd'absolutisme'". (Latour, 2012, p. 106)

6 "Mas há uma questão bem mais importante aqui. A teoria perspectivista ameríndia está de fato, como afirma Arhem, supondo uma multiplicidade de representações sobre o mesmo mundo? Basta considerar o que dizem as etnografias, para perceber que é o exato inverso que se passa: todos os seres veem ('representam') o mundo da mesma maneira - o que muda é o mundo que eles veem." (Viveiros de Castro, 2011, p. 378)

7 Philipe Descola viria a retomar essa formulação de Viveiros de Castro no livro que será analisado adiante: "[...] Viveiros de Castro a-t-il eu raison de souligner que l'opposition fondamentale entre ces deux modes d'identification reposait pour l'essentiel sur une inversion symétrique: l'animisme est 'multinaturaliste', selon lui 
puisque fondé sur l'hétérogénéité corporelle de classes d'existants pourtant dotés d'un esprit et d'une culture identiques, tandis que le naturalisme est 'multiculturaliste' en ce qu'il adosse au postulat de l'unicité de la nature la reconnaissance de la diversité des manifestations individuelles et collectives de la subjectivité". (Descola, 2005, p. 242)

8 “Je l'appellerai volontiers l'universalisme relatif, non par provocation ou goût des antiphrases, mais en prenant l'épithète 'relatif' au sens qu'elle a dans 'pronom relatif, c'est-à-dire qui se rapporte à une relation. L'universalisme relatif ne part pas de la nature et des cultures, des substances et des esprits, des discriminations entre qualités premières et qualités secondes, mais des relations de continuité et de discontinuité, d'identité et de différence, de ressemblence et de dissimilitude que les humains établissent partout entre les existants au moyen des outils hérités de leur phylogenèse: un corps, une intentionnalité, une aptitude à percevois des écarts distinctifs, la capacité de nouer avec un autrui quelconque des rapports d'attachement ou d'antagonisme, de domination ou de dépendence, d'échange ou d'appropriation, de subjectivation ou d'objetivation."

9 Paradigmas consolidados a partir da filosofia cartesiana e que foram disputados nas últimas décadas por etnólogos como Ingold e Berque e neurofisiologistas como James Gibson, estando aqueles "confrontés", segundo Philipe Descola, "dans les sociétés qu'ils étudiaient à des modes de relation à l'environnement dont les formulations locales cadraient mal avec le dualisme classique du monde et de l'esprit, du sujet et de l'objet ou de l'intellection et de la sensation". (Descola, 2005, p. 261)

${ }^{10}$ O termo "Modernos" não é de modo algum autoexplicativo. Para Latour, o relato usual que deseja superar poderia ser assim resumido: "A modernidade possui tantos sentidos quantos forem os pensadores ou jornalistas. Ainda assim, todas as definições apontam, de uma forma ou de outra, para a passagem do tempo. Através do adjetivo moderno, assinalamos um novo regime, uma aceleração, uma ruptura, uma revolução do tempo. Quando as palavras 'moderno', 'modernização' e 'modernidade' aparecem, definimos, por contraste, um passado arcaico e estável. Além disso, a palavra encontra-se sempre colocada em meio a uma polêmica, em uma briga onde há ganhadores e perdedores, os Antigos e os Modernos. 'Moderno', portanto, é duas vezes assimétrico: assinala uma ruptura na passagem regular do tempo; assinala um combate no qual há vencedores e vencidos." (Latour, 1994, p. 15). A compreensão das respostas de Latour exige a leitura integral do volume, para começar.

11 "Voilà ce qui nous est arrivé ; voilà ce dont il s'agit d'hériter ; et maintenant, qu'allons-nous faire de cette anthropologie historique ou, mieux, de cette ontologie régionale?". (Latour, 2012, p. 11 )

12 Latour o defende em EME nestes termos: "Mais, à l'inverse, on va peut-être bénéficier d'un pluralisme ontologique qui va permettre de peupler les cosmos d'une façon un peu plus riche et, par conséquent, de commencer sur une base plus équitable, la comparaison des mondes - la pesée des mondes. On ne s'étonnera donc pas que je parle dans tout ce qui suit des "êtres " de la science, de la technique, etc. Au fond, il nous faut reprendre la vieille question « qu'est-ce que ?» (qu'est-ce que la science ? quelle est l'essence de la technique ? etc.), mais en découvrant des êtres aux propriétés chaque fois différentes. Ce qu'on va perdre en liberté de parole - les mots portent leur poids d'être - on va le regagner par le pouvoir d'entrer en contact avec des types d'entités qui n'avaient plus de place dans la théorie et pour 
lesquelles il faudra chaque fois trouver un langage qui leur soit ajusté. Entreprise périlleuse, si l'en est". (Latour, 2012, p. 33)

13 "Normalista indolente e filósofo medíocre, eu descobrira na leitura dos clássicos da sociologia uma feliz compensação para o purgatório da agrégation. [...] Insatisfeito com a exegese filosófica e com a submissão exclusiva ao trabalho da teoria pura, decidi finalmente abandonar meus colegas ao seu fervor metafísico. Em vez de dissertar sobre as condições de produção da verdade, eu ia me afundar nas trevas do empirismo e me esforçar para explicar os fatos da sociedade". (Descola, 2006, p. 46)

${ }^{14}$ O empirismo que impeliu o início da carreira de Descola é o mesmo que continua a animar, afinal, a teoria de Bruno Latour. Em seu caso, almeja um empirismo à moda de William James, “[...] rien que l'expérience, oui, mais pas moins que l'expérience". (Latour, 2012, p. 10)

15 "La contradiction est ordinairement résolue par le partage des tâches: tandis que certains privilégient l'exercice d'une intuition rendue démonstrative par la cohérence des enchaînements logiques qu'elle autorise, d'autres - moins nombreaux, il est vrai - se consacrent à la recherche de séries récurrentes empiriquement vérifiables par le travail statistique". (Descola, 1986, p. 2)

16 “De ces auteurs, notre petit groupe d'agrégatifs ne connaissait généralement que ce qu'il faut savoir pour faire une leçon brillante sur la notion de structurem c'est-àdire très peu de choses". (Descola, 1986, p. 3)

17 “Depuis Oviedo jusqu'à Buffon, cet univers original est apparu aux savants européens comme une sorte de conservatoire botanique et zoologique, très accessoirement peuplé par des hommes". (Descola, 1986, p. 10)

18 O plano doméstico é de fato o responsável pelo continuum que Descola enxergava entre natureza e cultura: "Or, cette multiplicité fragmentée d'appariements avec le monde naturel est organisée par l'idée fondamentale que la nature est l'enjeu de rapports sociaux identiques à ceux qui ont la maison pour théâtre. La nature n'est donc ni domestiquée ni domesticable, elle est tout simplement domestique [...]. Cette spectaculaire réduction du fouillis sylvestre à l'ordre horticole indique assez que le rapport de la nature à la culture se donne moins à voir comme une césure que comme un continuum". (Descola, 1986, p. 398)

19 "Não se trata, então, de refutar teses de qualquer das teorias em competição (a refutação não mata teorias), mas de preservar 'fatos' bons de cada teoria (caráter estruturado do simbolismo; viabilidade adaptativa da prática Achuar) e, talvez, apontar para fatos novos".

20 “Contre l'historicisme, et sa foi naïve dans l'explication par les causes antécédentes, il faut rappeler avec force que seule la connaissance de la structure d'un phénomène permet de s'interroger de façon pertinente sur ses origines". (Descola, 2005, p. 13-14)

21 "Les convictions intimes qu'un anthropologue se forge au sujet de la nature de la vie sociale et de la condition humaine résultent souvent d'une expérience ethnographique très particularisée, acquise auprès de quelques milliers d'individus qui ont su instiller en lui des doutes si profonds quant à ce qu'il tenait auparavant comme allant de soi que toute son énergie se déploie ensuite à les mettre en forme dans une enquête systématique". (Descola, 2005, p. 21)

22 A expressão foi aparentemente coletada na obra de Latour: "[...] collectives (the technical term I use to make it clear that it is neither a question of nature or of cultures)". (Latour, 2007, p. 16) 
${ }^{23}$ Esta síntese de Viveiros de Castro apresenta explicações adicionais quanto às discrepâncias entre esse modelo e o ocidental: “A proposição presente nos mitos indígenas é: os animais eram humanos e deixaram de sê-lo, a humanidade é o fundo comum da humanidade e da animalidade. Em nossa mitologia é o contrário: os humanos éramos animais e "deixamos" de sê-lo, com a emergência da cultura etc. Para nós, a condição genérica é a animalidade: "todo mundo" é animal, só que alguns (seres, espécies) são mais animais que os outros: nós, os humanos, certamente somos os menos animais de todos e 'esse é o ponto', como se diz em inglês. Nas mitologias indígenas, muito ao contrário, todo mundo é humano, apenas alguns desses humanos são menos humanos que os outros. Vários animais são muito distantes dos humanos, mas são todos ou quase todos, na origem, humanos ou humanóides, antropomorfos ou, sobretudo, antropológicos" isto é, comunicam-se com(o) os humanos. Tudo isso vai ao encontro da atitude que se costuma chamar de "animismo", a pressuposição ou intuição" pré-conceitual (o plano de imanência, diria Deleuze) de que o fundo universal da realidade é o espírito". (Sztutman, 2009, p. 33)

24 "Peut-être même est-ce mon interprétation de leur culture qui est fautive? Par défaut de perspicacité ou désir d'originalité, je n'aurais pas su ou voulu déceler l'agencement spécifique qu'aurait priz chez eux la dichotomie entre nature et société". (Descola, 2005, p. 25-26)

25 "Dans le Grand Nord comme en Amérique du Sud, la nature ne s'oppose pas à la culture, mais elle la prolonge et l'enrichit dans un cosmos où tout s'ordonne aux mesures de l'humanité". (Descola, 2005, p. 33-34)

${ }^{26}$ Concordância justificada por cumulativas investigações etnológicas e arqueológicas que comprovam a existência de uma cultura original americana não completamente devastada pela atividade colonial. "En témoignent les mythes, bien évidemment, ces variations ordonnées sur un substrat sémantique homogène, dont il est difiicile d'imaginner qu'ils ne procèdent pas d'une commune conception du monde, forgée au cours de mouvements millénaires d'idées et de populations". (Descola, 2005, p. 38)

27 "L'hypothèse servant de fil conducteur aux analyses qui vont suivre est que les schemes intégrateurs des pratiques dont nous avons examiné les mécanismes généraux au chapitre précédent peuvent être ramenés à deux modalités fondamentales de structuration de l'éxperience individuelle et collective, que j'appellerai l'identification et la relation". (Descola, 2005, p. 163)

28 Sempre atento às lacunas, Descola adverte que essas categorias não esgotam as possibilidades de estruturação da experiência, havendo que levar em conta também, no mínimo, a temporalidade, a espacialização, a figuração, a mediação e a categorização. (Descola, 2005, p. 166)

29 'Aussi faut-il préciser que mon entreprise n'est pas 'comparatiste' au sens habituel, et encore moins encyclopédique. Il ne s'agit pas pour moi de collectionner des phénomènes et de les classes par généralisation inductive dans des boîtes à spécimens, à la manière de Frazer ou de Radcliffe-Brown, mais de partir d'une hypothèse relativement abstraite et qui n'est peut-être qu'une expérience de pensée - les quatre manières de distribuer l'intériorité et la physicalité - dont je déduis des propriétés quanto aux diverses façons qu'ont les humains de structurer le monde et les usages auxquels il se prête, façons que j'illustre par des cas idéaltypiques empruntés à des régions de la planète suffisamment diverses pour que la variété des expériences que ces cas traduisent confère une certaine vraisemblance aux distinctions que j'opère. 
Les modes d'identification et de relation que j'isole n'ont donc pas pour finalité de rendre compte de tous les particularismes culturels et sociaux qu'auraient pu rapporter l'ethnographie et l'histoire - un tel projet serait en effet délirant; il faut les voir comme des outils heuristiques au moyen desquels il serait possibile de mieux comprendre pourquoi certain types de phénomènes étudiés de longue date par l'anthropologie sont compatibles ou non entre eux du fait de leurs propriétés de structure". (Descola, 2006, p. 430)

30 "These objects are neither empirical nor ideal, they are not an ad hoc synthesis of representations and practices; they are bundles of contrastive features abstracted from descriptions of social life in order to highlight some of its properties."

${ }^{31}$ On pourrait objecter avec raison que le monde et ses usages sont bien trop complexes pour être réduits à ce genre de combinaison élémentaire. Rappelons donc que les modes d'identification ne sont pas des modèles culturels ou des habitus localement dominants, mais des schèmes d'intégration de l'experience qui permettent de structurer de façon sélective le flux de la perception et le rapport à autrui en établissant des ressemblances et des différences entre les choses à partir des ressources identiques que chacun porte en soi: un corps et une intentionalité. Les principes qui régissent ces schèmes étant universels par hypothèse, ils ne sauraient être exclusifs les uns des autres et l'on peut supposer qu'ils coexistent en puissance chez tous les humains. L'un ou l'autre des modes d'identification devient certes dominant dans telle ou telle situation historique, et se trouve donc mobilisé de façon prioritaire dans l'activité pratique comme dans les jugements classificatoires, sans que ne soit pour cela annihilée la capacité qu'ont les trois autres de s'infiltrer occasionnellement dans la formation d'une représentation, dans l'organisation d'une action ou même dans la définition d'un champ d'habitudes.

32 A base lévi-straussiana que sustenta as formulações de diversos intelectuais da "virada ontológica" na Antropologia é, para Turner e outros, a origem dessa mecanicidade. Como explica Sáez, "[...] o fracasso do estruturalismo [...] reside na sua incapacidade de, uma vez elaborada essa síntese monumental de Mitológicas, realizar-se também como uma análise em níveis mais concretos, traçando grupos de transformação que descrevam conjuntos etnológicos reais. Se bem entendi, Turner desafia o estruturalismo a aplicar na terra o grau de formalização que desenhou no céu". (Sáez, 2012, p. 8)

33 "Pour paraphraser une célèbre formule de Kant, des structures sans contenu sont vides, des expériences sans formes, privées de signification". (Descola, 2005, p. 135)

34 "Pour raisonnable qu'elle soit, cette particularisation de l'habitus rend toutefois difficiles la comparaison des modalités de sa manifestation concrète et la saisie comme un ensemble structuré des diverses combinaisons où il intervient". (Descola, 2005, p. 138)

35 Pensa-se aqui nos procedimentos de construção dos fatos científicos como reconsiderados, anos atrás, por Bruno Latour e Steve Woolgar em "A vida de laboratório", livro no qual descreveram processos laboratoriais a partir de categorias literárias, sem qualquer pretensão de reduzir aqueles processos a meras ficções. Tratava-se, então, de reconhecer a descoberta como processo sociológico. "Quando colocamos a tônica no procedimento de construção das substâncias, quisemos afastar as descrições dos biotestes que consideram não problemáticas as relações entre significantes e significados. Opusemos aos cientistas que sustentam a ideia de que as inscrições podem ser representações ou indicadores de uma substância 'exterior' (out there) 
o argumento de que essas substâncias só eram construídas pelo próprio uso das inscrições. [...] Não atribuímos absolutamente aos cientistas a intenção de utilizar estratégias como o desvelamento de verdades dadas e até então dissimuladas. $\mathrm{Na}$ realidade, os objetos, (neste caso, as substâncias) são constituídos pelo talento criativo dos homens de ciência". (Latour; Woolgar, 1997, p. 131)

36 "Je ne vois pas non plus ou Bruno Latour - puisqu'il est embarqué avec moi dans cette galère - aurait pu écrire cette niaiserie que la science est un mythe parmi d'autres. Ou alors peut-être dans un sens très particulier que je partage avec lui comme avec les historiens et les sociologues qui s'occupent de ces questions : tous ces gens-la prennent en effet au sérieux les sciences, les circonstances de leur émergence et de leur consolidation, les pratiques qui les entretiennent, l'incidence des dispositifs de mesure et d'instrumentation sur la definition de leurs objets, les institutions qui rendent possibles leur exercice, et bien d'autres choses encore qu'ils étudient en consultant les carnets des expériences, les correspondances et les journaux personnels ou en menant leurs enquêtes directement dans les laboratoires ; mais ils restent en revanche assez perplexes devant la Science, cette majestueuse abstraction dont ils preferent laisser la caracterisation aux epistemologues patentes et aux scientifiques que demange le prurit philosophique". (Descola, 2006, p. 432)

37 Não se deve perder de vista a ampla colaboração entre Descola e Viveiros de Castro, para além das intensas discordâncias apontadas. Este não tem qualquer dificuldade em reconhecer a relação de proximidade entre as noções de animismo e perspectivismo, dentre outros aspectos (Viveiros de Castro, 2002, p. 361; 466-467 et passim).

\section{Referências}

ALMEIDA, Mauro W. B. Dilemas da razão prática: simbolismo, tecnologia e ecologia na floresta amazônica. Anuário Antropológico, Brasília, DF, n. 86, 1988.

BLOCH, Maurice. Par-delà nature et culture (review). Annales. Histoire, Sciences Sociales, 62 e année, n. 1, Formes de la généralisation, 2007.

DESCOLA, Philippe. La nature domestique: Symbolisme et praxis dans l'écologie des Achuar. Paris: Éditions de la Maison des Sciences de l'Homme, 1986.

DESCOLA, Philippe. Par-delà nature et culture. Paris: Gallimard, 2005.

DESCOLA, Philipp. As lanças do crepúsculo: relações Jivaro na Alta Amazônia. São Paulo: Cosac Naify, 2006.

DESCOLA, Philippe. Soyez réalistes, demandez l'impossible: Réponse à Jean-Pierre Digard. L'Homme, Paris, n. 177/178, Jan-Jun, 2006.

DESCOLA, Philippe. A antropologia da natureza de Philippe Descola. Entrevista. Topoi. Revista de História, Rio de Janeiro, v. 14, n. 27, 2013.

DESCOLA, Philippe. Modes of being and modes of predication. HAU: Journal of Ethnographic Theory, Cambridge, v. 4, n. 1, 2014. 
LATOUR, Bruno. Jamais fomos modernos: ensaio de antropologia simétrica. São Paulo: Editora 34, 1994.

LATOUR, Bruno; WOOGAR, Steve. Laboratory life: the construction of scientific facts. Princeton: Princeton University Press, 1996.

LATOUR, Bruno; WOOLGAR, Steve. A vida de laboratório: a produção dos fatos científicos. Rio de Janeiro: Relume Dumará, 1997.

LATOUR, Bruno. Reassembling the social: an introduction to actornetwork theory. Oxford: Oxford University Press, 2005.

LATOUR, Bruno. The recall of modernity. Cultural Studies Review, Melbourne, v. 13, n. 1, 2007.

LATOUR, Bruno, Perpesctivismo: "tipo" ou "bomba"? Primeiros Estudos, São Paulo, n. 1, 2011.

LATOUR, Bruno. Enquête sur les modes d'existence: une anthropologie des Modernes. Paris: La Découverte, 2012.

SÁEZ, Oscar Calavia. Do perspectivismo ameríndio ao índio real. Campos, Curitiba, n. 13, n. 2, 2011.

SZTUTMAN, Renato (Org.). Eduardo Viveiros de Castro: encontros. São Paulo: Cosac Naify, 2009.

VIVEIROS DE CASTRO, Eduardo. A inconstância da alma selvagem: e outros ensaios de antropologia. São Paulo: Cosac Naify, 2002.

VIVEIROS DE CASTRO, Eduardo. "Transformação" na antropologia, transformação da "antropologia". Mana, Rio de Janeiro, v. 18, n. 1, 2012. 